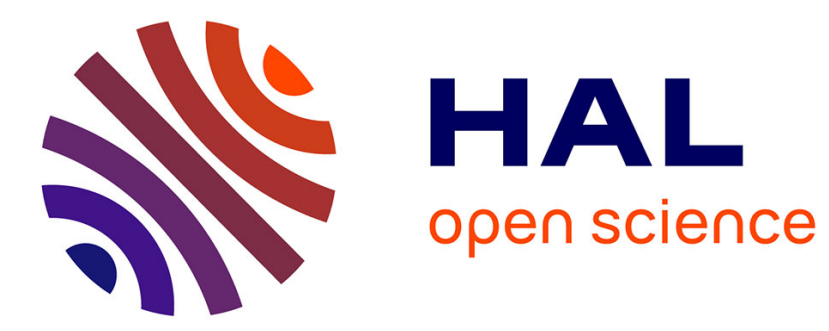

\title{
Validation in Agent-based Models: An Investigation on the CATS model
}

Carlo Bianchi, Pasquale Cirillo, Mauro Gallegati, Pietro A. Vagliasindi

\section{To cite this version:}

Carlo Bianchi, Pasquale Cirillo, Mauro Gallegati, Pietro A. Vagliasindi. Validation in Agent-based Models: An Investigation on the CATS model. Journal of Economic Behavior and Organization, 2008, 67 (3-4), pp.947. 10.1016/j.jebo.2007.08.008 . hal-00614679

\section{HAL Id: hal-00614679 \\ https://hal.science/hal-00614679}

Submitted on 15 Aug 2011

HAL is a multi-disciplinary open access archive for the deposit and dissemination of scientific research documents, whether they are published or not. The documents may come from teaching and research institutions in France or abroad, or from public or private research centers.
L'archive ouverte pluridisciplinaire HAL, est destinée au dépôt et à la diffusion de documents scientifiques de niveau recherche, publiés ou non, émanant des établissements d'enseignement et de recherche français ou étrangers, des laboratoires publics ou privés. 


\section{Accepted Manuscript}

Title: Validation in Agent-based Models: An Investigation on the CATS model

Authors: Carlo Bianchi, Pasquale Cirillo, Mauro Gallegati, Pietro A. Vagliasindi

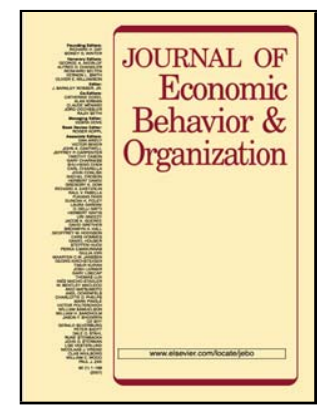

PII:

S0167-2681(07)00172-2

DOI: doi:10.1016/j.jebo.2007.08.008

Reference: JEBO 2144

To appear in: Journal of Economic Behavior \& Organization

Received date: $\quad 2-5-2006$

Revised date: $\quad 29-8-2007$

Accepted date: $\quad$ 29-8-2007

Please cite this article as: Bianchi, C., Cirillo, P., Gallegati, M., Vagliasindi, P.A., Validation in Agent-based Models: An Investigation on the CATS model, Journal of Economic Behavior and Organization (2007), doi:10.1016/j.jebo.2007.08.008

This is a PDF file of an unedited manuscript that has been accepted for publication. As a service to our customers we are providing this early version of the manuscript. The manuscript will undergo copyediting, typesetting, and review of the resulting proof before it is published in its final form. Please note that during the production process errors may be discovered which could affect the content, and all legal disclaimers that apply to the journal pertain. 


\title{
Validation in Agent-based Models: An Investigation on the CATS model.
}

\author{
Carlo Bianchi \\ Dipartimento di Scienze Economiche - Università di Pisa \\ Pasquale Cirillo \\ DEP/IMQ - Università Bocconi Milano \\ Mauro Gallegati \\ DEA/SIEC, Università Politecnica delle Marche
}

Pietro A. Vagliasindi

Dipartimento di Diritto, Economia e Finanza Internazionale - Università di Parma

28th August 2007 


\section{Introduction}

Mainstream economics adopts the classical mechanical approach of 19th century physics, based upon the reductionist principle, according to which one can understand the aggregate simply by analyzing its single elements. The microfoundation of macroeconomics in the (New) Classical tradition is based on the hope that the aggregate behavior is the magnification of the single agent's behavior on a larger scale. The application of the reductionist framework implies that the so-called overlapping principle holds true, that the dynamics of a (linear) model can be decomposed into its constituent parts through the representative agent (RA) framework.

The microeconomic foundations of general equilibrium models must be based, according to mainstream economics, on an optimizing RA, fully rational and omniscient. Unfortunately, "there are no assumptions on [...] isolated individuals which will give us the properties of aggregate behavior which we need to obtain uniqueness and stability. Thus we are reduced to making assumptions at the aggregate level which cannot be justified by the usual individualistic assumptions. This problem is usually avoided in the macroeconomic literature by assuming that the economy behaves like an individual. Such an assumption cannot be justified in the context of the standard economic model and the way to solve the problem may involve rethinking the very basis on which this model is founded" (Hildenbrand and Kirman 1988, p. 239).

The quantum revolution of the last century radically changed the perspective in contemporary physics. According to the holistic approach, the aggregate is different from the sum of its components because of the interaction of particles. In the social sciences, a step in this direction is taken by the agent-based modeling (ABM) strategy.

Agent-based models, which are increasingly applied in economics (Tesfatsion 2007, Axelrod 1997), have been developed to study the interaction of many heterogeneous agents. In a sense they are based on new microfoundations, according to a bottom-up approach. They follow a holistic methodology as opposed to the reductionist approach of the mainstream economics. One builds a model starting from simple behavioral rules at the single agent level. Through interactions some aggregate statistical regularities emerge so that they can not be inferred from the individual level. This emergent behavior often feeds back to individual agents, making their rules change (they may evolve in an adaptive way). According to this approach, macroeconomics is not a set of equations that occurs by summation and averaging of the individual decisions, but it is a SOC (Self-Organized Critical) phenomenon that rises from the micro-level.

As already mentioned, ABM and simulations have been extensively used in many scientific fields, including economics, in the last decade (Axelrod 1997, Axtell 2000). However, in recent years only, researchers have started considering the issue of validation: that is whether a model and its results may be considered correct. As Sargent (1998, p. 53) puts it, "This concern is addressed through model verification and validation. Model validation is usually defined to mean substantiation that a computerized model within its domain of appli- 
cability possesses a satisfactory range of accuracy consistent with the intended application of the model". This is not at all a secondary problem; in fact, only a correct model can be considered a suitable model.

In this paper we deal with some validation experiments of a simplified version of the model proposed in Gallegati et al. (2003a, 2005), the so called CATS (Complex Adaptive Trivial System) model.

The CATS model has been extensively used (see, for example, Gallegati et al. 2003b, 2004, 2005) to replicate a large number of scaling type stylized facts with a remarkable degree of precision, and for these purposes, the simulation of the model has been performed entering ad hoc parameters' values and using the same initial set up for all the agents involved in the experiments. It must be recalled that the above mentioned analyses have been performed following Kaldor's suggestion: "construct a hypothesis that could account for these stylized facts, without necessarily committing himself on the historical accuracy" (1965, p. 178).

In this paper our intentions are more ambitious: using an initial set up of actual data (a sample of Italian firms in 1996) we aim to verify whether the CATS model, simulated over a period for which actual data are fully available (the interval 1996-2001), is an acceptable representation of the real system. In other words we intend to perform an ex-post validation of the model.

Alternative distributional and goodness-of-fit tests, discussed in Prabhakar et al. (2003) and Kleiber and Kotz (2003), are performed, and some graphical tools (Embrechts et al. 1997) are proposed in order to give the reader a quick comprehension of actual and simulated data.

In the validation exercise, over the simulation period 1996-2001, we use a sample of 6422 Italian firms included in the AIDA database. The model parameters have been estimated using actual data, and the initial set up consists of the sample data of the year 1996. The CATS model is then simulated over the period 1996-2001, and the simulations' results are ex-post validated with respect to actual data.

The model reproduces, in a short (medium) term horizon, a good percentage ( $81 \%$ in 2001) of the output actual data. The two samples (simulated and observed data) belong to the same distribution with a confidence interval of 95\%. Moreover the model also reproduces the firms' growth dynamics at a micro level, while less satisfying is the simulation for the behavior of the very small and very large firms.

The papers is organized as follows. Section 2 presents the state of the art for the validation of agent-based models, Section 3 introduces the model we have studied and validated, Section 4 describes the database we used and the empirical evidence we aim to investigate, Section 5 shows the proceeding of the validation procedure, and Section 6 concludes. 


\section{Empirical Validation of Agent-based Models}

As Leigh Tesfatsion points out in her important website on Agent-based Computational Economics ${ }^{1}$, the validation of ACE models is becoming one of the major points in the agenda of those researchers who work according to the agent-based approach.

In the literature, looking at the main methodological aspects, there are three different ways of validating computational models:

1. Descriptive output validation, matching computationally generated output against already available actual data. This kind of validation procedure is probably the most intuitive one, and it represents a fundamental step towards a good model's calibration.

2. Predictive output validation, matching computationally generated data against yet-to-be-acquired system data. Obviously, the main problem concerning this procedure is essentially due to the delay between the simulation results and the final comparison with actual data. This may cause some difficulties when trying to study long time phenomena. Anyway, since prediction should be the real aim of every model ${ }^{2}$, predictive output validation must be considered an essential tool for an exhaustive analysis of a model meant to reproduce reality.

3. Input validation, ensuring that the fundamental structural, behavioral and institutional conditions incorporated in the model reproduce the main aspects of the actual system. This is what we can call ex ante validation; the researcher, in fact, tries to introduce the correct parameters in the model before running it. The information about parameters can be obtained analyzing actual data, thanks to the common empirical analysis. Input validation is obviously a necessary step one has to take before calibrating the model.

In this paper we analyze points 1 and 3 . As far as predictive validation is concerned, we hope to develop it in the near future.

Since the empirical validation of agent-based models is still a new topic, at the moment there are only a limited number of contributions in the literature dealing with it, as summarized below.

In their paper, Axtell et al. (1996) develop the basic concepts and methods of an alignment process for agent-based models. In particular they show how alignment can be used to test whether two different computational models can be considered similar in terms of behavior and output.

In Carley (1996), there's a first stress on model validation issues, even if the attention of the author is still focusing on computational modeling in general.

\footnotetext{
${ }^{1} \mathrm{http}: / /$ www.econ.iastate.edu/tesfatsi/empvalid.htm

${ }^{2}$ Validation is not the end of the study process. Indeed, it must be considered an intermediate step, necessary to ameliorate the model in order to make predictions.
} 
A very interesting experiment can be found in the paper by Gilli and Winker (2003), in which the authors present an agent-based exchange market model and introduce a global optimization algorithm for calibrating the model's parameters via simulation.

In Troitzsch (2004), there is a comprehensive list of all the issues concerning the validation of simulation models to describe and predict real world phenomena.

In Fagiolo et al. (2007), one can finally find a very interesting discussion about the ways agent-based modelers have tried to face the empirical validation of their models. The authors briefly review the standard approaches to model validation employed by mainstream economists and then point out the main differences dealing with ABM validation. The paper concludes with some suggestions regarding the methodological aspects of validation.

Finally, without any presumption of being complete and exhaustive, we cannot forget the mainly theoretical and methodological contributions by Sargent (1998), Klevmarken (1998), Epstein (1999) and Judd (2006).

\section{The CATS model}

The model we present was first introduced in Gallegati et al. (2003a) to study financial fragility and power laws. Here, it's modified to better reproduce actual data, according to the input validation principle we have mentioned above.

Following the ACE philosophy, it is a simple model, since it makes use of straightforward and clear-cut assumptions. Simplicity is one of the main qualities of agent-based models, which are considered good models only if able to reproduce and explain empirical evidences without being too complicated or making too many assumptions. In other words, the simpler the model is, the easier are reading and interpreting the results.

Consider a sequential economy ${ }^{3}$, with time running $t=1,2, \ldots$, populated by firms and banks. Two markets are opened in each period: the market for a homogeneous produced good and the market for credit. As in the levered aggregate supply class of models first developed in Greenwald and Stiglitz (1990, 1993), our model is fully supply-determined in the sense that firms can sell all the output they optimally decide to produce. Due to informational imperfections in the equity market, firms can raise funds only from the credit market, apart from retained profits from previous periods. This assumption seems to reflect the examined reality in Italy since new equity issues were rarely a financial option for Italian firms in the observed period. Moreover, the full distribution of dividends to shareholders was expensive due to the fiscal system. In a perfect environment, without taxes, corporations would not have preferences among these financial options, as shown by the Modigliani-Miller theorem.

Hence, in our setting, the demand for credit is related to investment expenditure, and it is fully satisfied at the fixed banks' interest rates (i.e. total credit

\footnotetext{
${ }^{3}$ In a sequential economy (Hahn 1982) spot markets open at given dates, while future markets do not operate.
} 
supply always equals the demand for it). This hypothesis helps us to identify a suitable proxy of the individual interest rates (namely, the average interest rate) since we have no reliable information related to them.

Let us then briefly describe the main features of the model in the remaining part of the section.

At any time $t$, the economy consists of $N_{t}$ firms, each belonging to two different sets (small firms and large ones) ${ }^{4}$, depending on their size, and facing different levels of risk (price shocks). This assumption is different from the original one (Gallegati et al. 2003a) with a single risk level.

Every firm $i \in N_{t}$ produces the output $Y$ according to a linear production function, in which capital $\left(K_{i t}\right)$ is the only input ${ }^{5}$ :

$$
Y_{i t}=\phi_{i t} K_{i t}
$$

For each firm $i$ the productivity $\phi_{i t}$ in $t=1$ corresponds to its actual productivity (estimated on the AIDA data in 1996), and it evolves according to the following formula:

$$
\phi_{i t}=\phi_{i t-1}+\varrho_{i t} \phi_{i t-1}^{2}, \quad \text { where } \varrho_{i t}=\frac{M}{2}
$$

with $M \sim U(0,1)$, if the firm is small, and to

$$
\phi_{i t}=\phi_{i 1}
$$

if large. All this reproduces the evidence from our database, reported in Figure 1 , where one can see the evolution of the average productivity for small and big firms for actual and simulated data. It clearly emerges that the growth rates of productivity are decreasing in firms' size, contradicting Gibrat's law for means ${ }^{6}$.

Figure 1: Evolution of average productivity for small and big firms from 1996 to 2001. Actual (straight lines with pluses) and simulated (dotted lines with

$$
\text { diamonds) data. }
$$

Each firm's demand for goods is affected by an iid idiosyncratic real shock. Since arbitrage opportunities are imperfect, the individual selling price is the random outcome of a market process around the average market price $P_{t}$ of the output, according to the law $P_{i t}=u_{i t} P_{t}$, where $E\left(u_{i t}\right)=\mu$ and $\sigma_{u_{i t}}^{2}<$ $+\infty$. Actual data suggest splitting the price generator process into two different

\footnotetext{
${ }^{4}$ According to the Italian Fiscal Law, to which we referred in writing this paper, a firm is considered "small" if it has less than 50 employees, "medium" if it has between 51 and 250 employees and "large" if it has more than 250 employees. In our sample, the percentage of firms is: $\approx 56 \%$ small, $\approx 31 \%$ medium, $\approx 13 \%$ large. In 1996 the smallest firm shows 2 employees, while the largest one 7308.

${ }^{5}$ Capital stock never depreciates.

${ }^{6}$ This is not the only evidence in the AIDA database contradicting Gibrat's law. As we will see in what follows (section 5), power law behaviors in firms' size distributions and Laplacian growth rates are an unambiguous negation of Gibrat's prediction, at least in its strongest version. For further details see Cirillo (2007), section 2.
} 
processes, depending on firms' size. For the sake of simplicity we assume that $u_{i t}$ follows two different uniform distributions; small firms get a high average price and a stronger volatility, while big firms face more concentrated prices with a lower mean. This assumption has a justification in the analysis of actual data: small firms, in fact, show a stronger volatility in their revenues and profits.

Summarizing, if $U_{1}$ is the distribution of $u_{i t}$ if $i$ is small and $U_{2}$ if $i$ is large, we have that $\mu^{U_{1}}>\mu^{U_{2}}$ and $\sigma_{U_{1}}^{2}>\sigma_{U_{2}}^{2}$.

Since, by assumption, credit is the only external source of finance for firms, the firm can finance its capital expenditure by recurring to net worth $\left(A_{i t}\right)$ or bank loans $\left(L_{i t}\right)$, that is $K_{i t}=A_{i t}+L_{i t}$. At the exogenous real interest rate $\bar{r}$, at each time $t$ debt commitments for every firm are equal to $\bar{r} L_{i t}$. Since for the sake of simplicity there are no dividends distributed to shareholders, financing costs equal debt commitments. Therefore, profit/loss $\left(\pi_{i t}\right)$ in real terms is

$$
\pi_{i t}=u_{i t} Y_{i t}-\bar{r} L_{i t}
$$

In our model a firm goes bankrupt if its net worth becomes negative, that is to say $A_{i t}<0$. The law of motion of $A_{i t}$ is, for hypothesis,

$$
A_{i t}=A_{i t-1}+\pi_{i t}
$$

As in Greenwald and Stiglitz (1993), we assume that the probability of bankruptcy $\left(\operatorname{Pr}^{b}\right)$ is directly incorporated into the firm's profit/loss function: bankruptcy is costly and increasing with the firm's size. In particular we have chosen a quadratic cost function:

$$
C^{b}=c Y_{i t}^{2} \quad c>0
$$

Finally, each firm, by maximizing its objective function, determines its optimal capital stock $K_{i t}^{*}$,

$$
\max _{K_{i t}} \Gamma_{i t}=E\left(\pi_{i t}\right)-E\left(C^{b}\right)
$$

and the demand for credit.

\section{The Database and the Empirical Evidence}

All our validation experiments, together with the subsequent empirical analysis, are based on firm-level observations from the AIDA database for the period 19962001, AIDA, formerly developed by the Italian Chambers of Commerce, is now a subset of AMADEUS, a comprehensive pan-European database elaborated by Bureau Van Dijk ${ }^{7}$.

Thanks to several queries on the database, we have collected a sample of 6422 Italian non-financial firms, all satisfying the following: (i) no missing data in each year, and (ii) reliable data for capital, employees and costs. For each firm

\footnotetext{
${ }^{7}$ For more information: http://amadeus.bvdep.com
} 
and year, we have data on equities, long term debts and loans, short term debts, total capital, gearing ratio, solvency ratio, debt ratio, number of employees, cost of employees and revenues.

Recent explorations (Gallegati et al. 2007) in industrial dynamics have detected three empirical regularities that are so widespread across countries and persistent over time as to be characterized as universal laws:

1. The distribution of firms' size is right skewed and can be described by a Zipf or power law probability density function (Gallegati et al. 2003b, Gaffeo et al. 2003, Axtell 2001, Ramsden and Kiss-Haypal 2000, Okuyama et al. 1999; Quandt 1966a-b, Mandelbrot 1960, Simon 1955);

2. Firms' growth rates are Laplace distributed, belonging to the Subbotin's Family (Stanley et al. 1996, Bottazzi and Secchi 2005);

3. There is a power law relation between the variance of the size growth rates and the size itself (Stanley et al. 1996, Gabaix et al. 2003).

Gallegati et al. (2005) have shown analytically that 1-3 determine several industrial, financial and business cycle facts (see that paper for a review of the empirical literature.) A model should therefore be able to replicate the empirical evidence 1-3, and our validation exercise is focused on it.

The following section will present the validation exercise (i.e. if the above presented CATS model successfully deals with the evidence 1-3).

\section{$5 \quad$ Simulation and Results}

Our validation exercise is run with a sample of 6422 firms over the period 19962001.

The validation procedure we have used is new for agent-based models ${ }^{8}$, but it is based on some well-known results of extreme value theory, mainly as far as the analytical tests are concerned (for a reference see Embrechts et al. 1997).

In $t=1996$ ( $t=1$ in simulations), each firm is initialized with its actual data from 1996: net worth, loans, productivity and so on. The market interest rate is exogenous and equal for all the firms. ${ }^{9}$

In each period actual data from the AIDA database are compared with the simulated data produced by the model. In particular our analysis can be divided into two different approaches: a pointwise analysis, meant to evaluate the evolution of the single firm in order to study the predictive power of the model, and a distributional analysis, whose aim is to look for regularities.

Our experiments can be considered a first ex-post validation of the CATS model, that is to say a first step, necessary to develop all the subsequent analysis.

\footnotetext{
${ }^{8}$ On JEBO website an appendix describing the procedure in detail is available.

${ }^{9}$ It decreases every year starting from $11.5 \%$ (1996) and arriving at $10 \%$ (2001).
} 


\subsection{Capital Distributions}

As far as the aggregate output is concerned, the model underestimates it slightly (average aggregate actual output over six years on log scale is equal to 10.3486; average aggregate simulated output over six years on log scale is equal to 10.1132 ), while the output volatility is almost identical $(\simeq 1.205$ vs. $\simeq 1.207)$. This is a first interesting result that underlines the ability of the model in replicating actual data ${ }^{10}$.

\subsubsection{Total Capital}

Let us now consider the total capital dynamics. Accepting a maximum deviation of $\pm 20 \%$ between observed and simulated data in 2001 (that is a composite yearly deviation rate of $3.5 \%$ ), we succeed in reproducing 5201 firms over 6422 (81\%). As Figure 4 shows, the tails of the firms' size distribution is not adequately fitted. Similar results can be found in the previous years (in 1997, for example, the percentage of fitted firms is $74 \%$, while in 1999 it's $77 \%$ ) and by analyzing the pooled distributions $(78 \%){ }^{11}$

In order to verify the real goodness of these results (verifying if they are due to the goodness of the model rather than to the characteristics of data such as few years, few firms with respect to the universe and so on), we have performed an empirical analysis of actual data. In Figure 3 one can observe the comparison, by the means of a Zipf's plot, between actual total capital in 1996 and 2001. The evidence is quite clear: there is a substantial difference between the two amounts of data (see also the boxplot in Figure 4). Accepting the usual $20 \%$ deviation, only $25 \%$ of the firms (essentially the smallest ones) can be considered as fitting the data. In fact, even if both distributions belong to the Paretian case ${ }^{12}$, their parameters are different. Several analytical tools, such as the Kolmogorov-Smirnov's statistics and the Kruskall-Wallis' test, confirm all this.

Even if we calculate the average growth rate of firms from 1996 to 2001 and then we multiply the initial data in 1996 for this coefficient, in 2001 we succeed in fitting "only" $62 \%$ of the firms. Since our model can fit $81 \%$ of them, it must be considered as performing better.

\footnotetext{
${ }^{10}$ Obviously, even if our sample is representative of the universe, we cannot completely exclude some slight dependence between output volatility and the number of firms in the system, which is surely influenced by the conditions we have imposed on the database (no lack of data, plausible capital values and so on). However, our experience of simulations with different datasets induce us to think that this detail should not be sufficient to invalidate our results.

${ }^{11}$ As in Ijiri and Simon (1997), the use of pooled distribution is possible since the single distributions show similar slopes.

In this paper, almost all the figures refer to year 2001.

${ }^{12}$ This is quite obvious; in only six years one cannot expect a distribution to change its shape and family. Finally this is what we can find in most of all the empirical studies about firms.
} 
Figure 2: Zipf's Plot of the total capital distributions: observed (plus) and simulated (diamonds).

Figure 3: Comparison between actual total capital in 1996 (plus) and 2001 (diamonds)

Figure 4: Boxplot of actual total capital in 1996 and 2001.

Figure 3 also shows that both observed and simulated capital distributions are particularly skewed, with fat right tails (decreasing linear relationship in the plot). This reproduces a widely accepted result (Zipf 1932), according to which firms' size is power law distributed ${ }^{13}$ (Axtell 2001, Gaffeo et al. 2003, Gabaix et al. 2003).

We have performed many graphical and analytical tests to check if our two samples (observed and simulated data) may be considered belonging to the same distribution.

A first Quantile-Quantile plot (Figure 5) supports the idea of a unique distribution for both samples, since there is a clear linear relationship between the observed and simulated data.

Figure 5: Q-Q Plot of the two Capital distributions

Another graphical test, the Box Plot (Figure 6), shows that the two distributions have many similarities. For example, the median (thick line ${ }^{14}$ ) is almost the same and it is not centered in the box, indicating two skewed distributions. Moreover, both distributions present a great number of outliers (red plus) in the right tails, underling the possible presence of fat tails.

Figure 6: Box Plot of simulated (left) and actual (right) Capital.

The same results are supported by the Generalized Kolmogorov-Smirnov Test ${ }^{15}$ with a confidence interval of $95 \%$. Therefore, it is possible to say that our two samples belong to the same distribution.

\footnotetext{
${ }^{13}$ A power law behaviour in firms' size is essentially due to the random iid micromultiplicative shocks (Solomon 1995) and the presence of the (bankruptcy) lower bound we have modelled. It is possible to show that a system with power laws tails distributions have divergent first and second moments, so the law of large numbers does not hold and the system is not ergodic.

${ }^{14}$ Line is red in the website version.

${ }^{15}$ The Generalised or Two Sample Kolmogorov-Smirnov test is a variation of the classical Kolmogorov-Smirnov test.

Given $\mathrm{N}$ data points $Y_{1}, Y_{2}, \ldots, Y_{n}$ the empirical distribution function (ECDF) is defined as

$$
F_{N}=\frac{n(i)}{N}
$$

where $n(i)$ represents the number of points less than $Y_{i}$. As one can see, this step function increases by $\frac{1}{N}$ for each data point.

The Kolmogorov-Smirnov test is based on the maximum distance between the ECDF and the theoretical cumulative distribution one wants to test $\left(F^{T}\right)$ :

$$
D=\max _{1 \leq i \leq N}\left|F^{T}\left(Y_{i}\right)-\frac{i}{N}\right| \text {. }
$$

On the contrary, the two sample K-S test, instead of comparing an empirical distribution
} 
In particular, excluding the right Paretian tails ${ }^{16}$, we found out that our data follow a Generalized Pareto Distribution (GPD) ${ }^{17}$, in particular a Pareto II type $(\xi \leq 0)$. Figure 7 shows a linear Pareto II Plot ${ }^{18}$ of the observed capital distribution (again, after excluding the largest firms).

Figure 7: Pareto II Plot of the actual capital (biggest 10\% trimmed)

The presence of Paretian behavior in the right tails of the two distributions is also supported by the Mean Excess Function versus Threshold Plot (MEPLOT). An upward sloping mean excess function, as in Figure 8, indicates a heavy tail in the sample distribution. That is why, thanks to the Hill's method ${ }^{19}$, we have decided to estimate the shape parameters of the two samples in order to see whether data have a similar behavior in the right tails.

Figure 8: Meplot of observed (above) and simulated (under) Capital.

function to the theoretical one, compares two different ECDF, that is

$$
D=\left|F_{1}(i)-F_{2}(i)\right|,
$$

where $F_{i}$ is the empirical distribution for sample $i$.

The generalised K-S statistic can be defined as:

$H_{0}: F_{1}=F_{2} \rightarrow$ the two samples come from the same distribution;

$H_{1}: F_{1} \neq F_{2} \rightarrow$ the two samples come from different distributions.

To decide the results of the test, the values of $D$ are compared to the critical values obtained from Kolmogorov and Smirnov's table.

${ }^{16}$ We have trimmed them after a threshold study based on graphical (for example looking for linearity in meplots) and analytical (studying the behavior of Hill's and Pickands' estimates) analysis. A very detailed description of the methodology is presented in Embrechts et al. (1997).

${ }^{17}$ Starting from the well-known Fisher-Tippett Theorem, which deals with the convergence of maxima, the GPD distribution represents one of the most important limiting cases.

Its functional form is

$$
H(x)=\left\{\begin{array}{ll}
1-\left(1+\xi \frac{x}{\beta}\right)^{-\frac{1}{\xi}} & \text { if } \xi \neq 0 \\
1-e^{-\frac{x}{\beta}} & \text { if } \xi=0
\end{array},\right.
$$

where $\beta>0$ and $x$ is such that $1+\xi x>0$ and $\xi$ is the shape parameter (tail index $\alpha=\frac{1}{\xi}$ ).

There are three different situations:

1. $\xi>0 \rightarrow$ GPD distribution becomes the classical Pareto distribution and shows fat tails;

2. $\xi=0 \rightarrow$ GPD distribution converges to the exponential distribution;

3. $\xi<0 \rightarrow$ GPD distribution; it is then known as Pareto II.

${ }^{18}$ That's a quantile-quantile plot with Pareto II coefficients.

${ }^{19}$ The well-known Hill's Estimator $\xi$, together with the Pickands' one, is the most used way to determine the shape parameter $\alpha=\frac{1}{\xi}$ of a distribution belonging to the GEV family.

In particular

$$
\xi=\frac{1}{k-1} \sum_{i=1}^{k-1} \ln x_{i, N}-\ln x_{k, N} \quad \text { for } k \geq 2,
$$

where $k$ is the upper order statistics and $N$ the sample size. 
Figure 9 reports the Hill's estimates of the shape parameter for the simulated capital, while Figure 10 refers to observed data. In the first case $\alpha=1.61$, while in the second one $\alpha=1,68$. Hence, the two parameters are very similar (Figure 11) and belong to the Paretian field $(0.8<\alpha<2)^{20}$, but we cannot claim that the two tails behave in the same way. Simulated capital, in fact, shows a slightly heavier tail (since its alpha is $\operatorname{lower}^{21}$ ), demonstrating that we slightly overestimated the observed values.

Figure 9: Hill Plot of the simulated capital

Figure 10: Hill Plot of the actual capital

Figure 11: Comparison of the two Hill Plots.

\subsubsection{Net Worth and Loans}

As far as net worth is concerned, accepting a maximum deviation of $\pm 20 \%$ between actual and simulated data in 2001, we succeed in reproducing 4944 firms over $6422(77 \%)^{22}$. This number is lower than that of total capital, indicating some more problems of fitting ${ }^{23}$.

Other positive results, see Figure 12, are the skewness of the two distributions and the presence of a clear Paretian behavior in both actual and simulated net worth. Hill's estimates of the shape parameters both show heavy right tails: actual data present $\alpha=1.52$, while the simulation produces $\alpha=1.48$.

Figure 12: Zipf's Plots of the net worth distributions: observed (plus) and simulated (diamonds) data

As far as the possibility of a unique distribution for the two samples, the twosided generalized Kolmogorov-Smirnov test rejects such a null hypothesis. On the contrary the one-sided right version of the test ${ }^{24}$ is not rejected, indicating that we get a better fitting of medium and big firms, but we fail in forecasting the smallest one.

The results we get about loans are very similar to those of the total capital: we succeed in fitting 5137 firms out of $6422(80 \%)$.

\footnotetext{
${ }^{20}$ Once again the results concerning the pooled distributions are very similar. The reason can be found in the words of Ijiri and Simon (p. 19): "We conclude that when two or more Pareto distributions are pooled together, the resulting distribution is Pareto if and only if all the distributions have similar slopes [...]. This result is important in dealing with the aggregation of empirical firm size distributions."

${ }^{21}$ As clearly showed in Kleiber and Kotz, the Pareto density has a polynomial right tail that varies at infinity with index $(-\alpha-1)$, implying that the right tail is heavier as $\alpha$ is smaller. ${ }^{22} 66 \%$ in $1997,73 \%$ in 1999

${ }^{23}$ In particular this may depend on the hypothesis of the model that 1) firms cannot raise funds on the equity market, 2) profits are entirely retained in the firm and 3) as suggested by the referee, that all firms face the very same interest rate. However, these simplifying hypothesis, typical of CATS model, do not seems to affect too much the robustness of our validation results.

${ }^{24} H_{0}: F_{1}^{+}(x)=F_{2}^{+}(x)$.

$H_{1}: F_{1}^{+}(x)>F_{2}^{+}(x)$.
} 
Moreover, similarly for total capital, both graphical and analytical tests support the idea of a unique distribution for both actual and simulated debt data (Figure 13).

Figure 13: Zipf's plot of loans: observed (plus) and simulated (diamonds).

As in Fujiwara (2004), the distribution of loans is also power law. The Hill's estimates of the shape parameters of the Paretian right tails are $\alpha=1.71$ for the actual data and $\alpha=1.58$ for the simulated ones, demonstrating an overestimate of biggest firms.

Finally, analyzing the ratio between net worth and debt we find out that, apart from some exceptions ${ }^{25}$, it is almost constant for each firm over time. In other words, if firm $i$ has a ratio of $x \%$ in 1996, it shows a very similar ratio in 2001 .

\subsection{Growth Rates}

As far as firms' growth rates are concerned, several studies (Bottazzi and Secchi 2005, Axtell 2001, Hall 1987) find a tent-shape behavior. In particular, the Laplace and Lévy distributions seem to provide the best fit (Gabaix et al. 2003).

We have investigated whether the empirical distributions of growth rates (in terms of capital) belong to the well-known Subbotin's family (Subbotin 1923), which represents a generalization of several particular cases such as Laplace and Gaussian distributions. The functional form of Subbotin's family is

$$
f(x, a, b)=\frac{1}{2 a b^{\frac{1}{b}} \Gamma\left(1+\frac{1}{b}\right)} e^{-\frac{1}{b}\left|\frac{x-\mu}{a}\right| b},
$$

where $\mu$ is the mean, $b$ and $a$ two different shape parameters and $\Gamma$ is the standard Gamma. If $b \rightarrow 1$ the Subbotin distribution becomes a Laplace, a Gaussian for $b \rightarrow 2$.

Using the maximum likelihood $\operatorname{method}^{26}$, we have estimated the three Subbotin's parameters on our data. Table 1 contains the results.

Figure 14: Empirical distributions of actual and simulated growth rates.

At a first glace, observed and simulated growth rates show several similarities:

1. The two means are very close to zero;

\footnotetext{
${ }^{25}$ While validating our model, we have conducted several experiments on interest rates, finding out that those firms showing a decreasing net worth/debt ratio are the same that obviously go bankrupt if the interest rates rise. This is interesting since the decreasing ratio is almost completely due to a monotonically deteriorating equity ratio (Beaver 1966, Gallegati et al. 2005). Moreover, surprisingly, all the firms that went bankrupt in our simulations were the same as those that really went bankrupt in 2002, showing a decreasing equity ratio.

Unfortunately, as already said, our data are not complete for 2002, so we prefer not to state this as a result.

${ }^{26}$ The results are very similar, using the method of moments.
} 


\begin{tabular}{|c|c|c|}
\cline { 2 - 3 } \multicolumn{1}{c|}{} & observed data & Simulated data \\
\hline$\mu$ & $-0.0030_{(0.0013)}$ & $0.0048_{(0.0021)}$ \\
\hline$a$ & $0.0587_{(0.0244)}$ & $0.0614_{(0.0238)}$ \\
\hline$b$ & $1.0184_{(0.3495)}$ & $1.0626_{(0.3664)}$ \\
\hline- loglik & $1.1528^{2}$ & 1.1549 \\
\hline
\end{tabular}

Table 1: Estimated Subbotin's Parameters (standard errors in brackets)

2. Since $b$ is very near to 1 , both distributions are in the field of attraction of the Laplacian case ${ }^{27}$. Figure 14 supports this evidence since it is tentshaped;

3. The values of $a$, the Laplacian shape parameter, are not very different in both cases, even if simulated data show slightly fatter tails $(0.061>0.059)$; see Figure 14.

Overall, the CATS model is able to mimic firms' growth dynamic, once again with some discrepancies as far as the tails are concerned.

\subsubsection{Growth Rates and Firms' Size}

In order to analyze the relationship between firms' size and firms' growth rates, we followed the methodology suggested by Gabaix et al. (2003). Stanley et al. (1996) find that large firms show a lower volatility of their growth rates; moreover, they show that this volatility $\left(\sigma_{\text {rates }}\right)$ linearly decreases with size $(S)$, or

$$
\ln \sigma_{\text {rates }}=-\alpha \ln S+\beta,
$$

with $\alpha \simeq 0.15$.

In order to investigate whether this relationship holds true for our actual and simulated data, we divided firms' size in four bins. Then we computed the standard deviation of their growth rates. Finally, we plotted a log-log graph of the average standard deviation of growth rates versus the average size in each bin.

For both observed and simulated data, our results are very similar to those presented in Gabaix et al. Figure 15 shows how the relationship we have found decreases with size. Our estimates of $\alpha$ are 0.1643 for the actual data and 0.1621 for the simulated ones (not far from Gabaix's 0.15). Once again, the CATS model successfully reproduces the empirical data.

In sum, we may say that the CATS model successfully passes the ex-post validation exercise of this section, with the only exception for very small firms.

Figure 15: Growth Rates Std vs Size (observed data)

\footnotetext{
${ }^{27}$ Some authors prefer a truncated Lévy distribution. The querelle is open. See Kleiber and Kotz.
} 


\section{Conclusions and future research}

Even if the results of the ex-post validation experiments discussed in section 4 are preliminary, they shows that in the interval 1996-2001, the simple CATS model, first introduced by Gallegati et al. (2003a) and slightly modified for these experiments (see section 3), has good capabilities in replicating empirical evidence, with few exceptions.

More reliable results could be obtained improving the specification of the model, better calibrating some key parameters using simulation based methods discussed, for example, in Gouriéroux and Monfort (1996) and in Klevmarken (1998), and carefully adjusting the dimensions of the sample used in the initial set up.

In future validation experiments, we intend to modify the model specification, endogenizing the banking sector (see Vagliasindi et al. 2006) and the price generator process and including a labor market module. Moreover, we hope to be able to work on a richer and more reliable dataset in order to generalize our results and correctly calibrate the model, taking also into account the specificity of the Italian situation.

\section{A Validation Procedure: some notes}

The aim of this appendix is to describe briefly the procedure we have used to validate the CATS model.

All the codes and the programs have been written in Fortran90@), while all the graphics have been developed with Matlab7 C).

As far as the simulation of the CATS model is concerned, it can be useful to stress the following aspects:

1. In $t=1$ (1996), when the simulation starts, every firm is initialized with its actual data from the database. These data are net worth, loans and productivity. The current version of the model has a recursive structure so that parameters $\phi_{i t}$ have been consistently estimated using, firm by firm, ordinary least squares. Then productivity evolves according to the laws of motions presented in 2 and 3 ;

2. The parameter $M$ in 2 follows an uniform distribution, whose support $(0,2)$ has been ad hoc calibrated, thanks to several replications;

3. The interest rate is equal to $11,5 \%$ in $1996(t=1)$ and decreases every year, arriving at $10 \%$ in 2001 . This reproduces the average behavior of the interests paid every year by firms in our database;

4. The two different uniform distributions we have used to model the idiosyncratic shocks on prices show support $(0.8,2.8)$ for small firms and support $(0.5,1.5)$ for the large ones. These supports have been inductively calibrated with a grid method, considering the results of several alternative replications, in order to get the best fitting values; 
5. Every year the following data are stored in order to be compared with actual data: net worth, loans, total capital, productivity, growth rates, paid interests, total output, aggregate output.

Our analysis of data can be divided into two different approaches: a pointwise analysis, meant to evaluate the evolution of the single firm, in order to study the predictive power of the model; and a distributional analysis, whose aim is to look for general regularities.

In Embrechts et al., one can find a quite complete list of all the tests a researcher should perform in analyzing data, while Kleijen (1998) deals with the theoretical implications of validation.

\section{References}

[1] Axelrod, R., 1997. Advancing the art of simulation in the social sciences. In: Conte, R., Hegselmann, R., Terna, P., (Eds). Simulating Social Phenomena. Berlin: Springer-Verlag, 21-40.

[2] Axtell, R., 2000. Why agents? On the varied motivations for agent computing in the social sciences. Center on Social and Economic Dynamics Working Paper 17.

[3] Axtell, R., 2001. Zipf's distribution of US firms sizes. Science 293, 18181820 .

[4] Axtell., R., Axelrdod, R., Epstein, J.M., Cohen, M.D., 1996. Aligning simulation models: a case study and results. Computational and Mathematical Organization Theory 1, 123-141.

[5] Beaver, W.H., 1966. Financial ratios as predictors of failure. Empirical Research in Accounting: Selected Studies. Supplement of the Journal of Accounting Research, 77-111.

[6] Bottazzi, G., Secchi, A., 2005. Explaining the distribution of firm growth rates. RAND Journal of Economics 37, 234-263.

[7] Carley, K., 1996. Validating Computational Models. Working Paper: www.econ.iastate.edu/tesfatsi/EmpVal/EmpVal.Carley.pdf

[8] Cirillo, P., 2007. Some considerations about Gibrat's law in Italy. Economics Letters, forthcoming.

[9] Embrechts, P., Mikosch, T., Kluppelberg, C., 1997. Modelling Extremal E vents. Berlin and New York: Springer-Verlag.

[10] Epstein, J., 1999. Agent-based computational models and generative social sciences. Complexity 4, 41-60. 
[11] Fagiolo, G., Moneta, A., Windrum, P., 2007. Empirical validation of agentbased models: alternatives and prospects. Journal of Artificial Societies and Social Simulation 10(2), 8 .

[12] Fujiwara, Y., 2004. Zipf law in firms bankruptcy. Physica A 337, 219-230.

[13] Gabaix, X., Gopikrishnan, P., Plerou, V., Stanley, H.E., 2003. A theory of power law distributions in financial markets fluctuations. Nature 423 , 267-70.

[14] Gaffeo, E., Di Guilmi, C., Gallegati, M., 2003. Power law scaling in the world income distribution. Economics Bulletin 15, 1-7.

[15] Gallegati, M., Giulioni, G., Palestrini, A., Delli Gatti, D., 2003a. Financial fragility, patterns of firms' entry and exit and aggregate dynamics. Journal of Economic Behavior and Organization 51, 79-97.

[16] Gallegati, M., Giulioni, G., Kichiji, N., 2003b. Complex dynamics and financial fragility in an agent-based model. Advances in Complex Systems 6, 770-779.

[17] Gallegati, M., Delli Gatti, D., Di Guilmi, C., Gaffeo, E., Giulioni, G., Palestrini, A., 2004. Business cycles fluctuations and firms' size distribution dynamics. Advances in Complex Systems 7, 1-18.

[18] Gallegati, M., Delli Gatti, D., Di Guilmi, C., Gaffeo, E., Giulioni, G., Palestrini, A., 2005. A new approach to business fluctuations: heterogeneous interacting agents, scaling laws and financial fragility. Journal of Economic Behavior and Organization 56, 489-512.

[19] Gallegati, M., Delli Gatti, D., Gaffeo, E., Giulioni G., Kirman, A., Palestrini, A., Russo, A., 2007. Complex dynamics and empirical evidence. Information Science 177, 1202-1221.

[20] Gilli, M., Winker, P., 2003. A global optimization heuristic for estimating agent-based models. Computational Statistics and Data Analysis 42, 299312 .

[21] Gourieroux, C., Monfort, A., 1996. Simulation-based Econometric Methods. Oxford: Oxford University Press.

[22] Greenwald, B.C., Stiglitz, J.E., 1990. Macroeconomic models with equity and credit rationing. In: Hubbard, R., (Ed). Information, Capital Markets and Investment. Chicago: Chicago University Press, 92-121.

[23] Greenwald, B.C., Stiglitz, J.E., 1993. Financial market imperfections and business cycles. The Quarterly Journal of Economics 108, 77-114.

[24] Hahn, F., 1982. Money and Inflation. Oxford: Blackwell Publishing. 
[25] Hall, B.E., 1987. The relationship between firm size and growth. Journal of Industrial Economics 35, 583-606.

[26] Hildebrand, W., Kirman, A., 1988. Equilibrium Analysis. Amsterdam: North Holland.

[27] Ijiri, Y., Simon, H.A., 1977. Skew Distributions and the Size of Business Firms. Amsterdam: North Holland.

[28] Kaldor, N., 1965. Capital accumulation and economic growth. In: Lutz, F.A., Hague, D.C., (Eds). The Theory of Capital. Proceedings of a Conference held by the International Economic Association. London: MacMillan, 177-222.

[29] Kleiber, C., Kotz, S., 2003. Statistical Size Distributions in Economics and Actuarial Sciences. New York: Wiley.

[30] Kleijnen, J.P.C., 1998. Experimental design for sensitivity analysis, optimization and validation of simulation models. In: Banks, J., (Eds). Handbook of Simulation. New York: Wiley, 173-224.

[31] Klevmarken, N.A., 1998. Statistical inference in microsimulation models: incorporating external information. Working Paper of Uppsala University, Department of Economics.

[32] Judd, K., 2006. Computationally intensive analysis in economics. In: Tesfatsion, L., Judd, K., (Eds). Handbook of Computational Economics 2. Amsterdam: North Holland, 881-892.

[33] Mandelbrot, B., 1960. The Pareto-Levy law and the distribution of income. International Economic Review 1, 79-106.

[34] Okuyama, K., Takayasu, H., Takayasu, M., 1999. Zipf's law in income distribution of companies. Physica A 269, 125-131.

[35] Prabhakar, M.D.N., Xie, M., Jiang, R., 2003. Weibull Models. New York: Wiley.

[36] Quandt, R.E., 1966a. On the size distribution of firms. American Economic Review 56, 416-432.

[37] Quandt, R.E., 1966b. Old and new methods of estimation and the Pareto distribution. Metrika 10, 55-82.

[38] Ramsden, J., Kiss-Haypal, G., 2000. Company size distribution in different countries. Physica A 277, 220-227.

[39] Sargent, T.J., 1998. Verification and validation in simulation models. Proceedings of 1998 Winter Simulation Conference, 52-64. 
[40] Simon, H.A., 1955. On a class of skew distribution functions. Biometrika $42,425-440$.

[41] Solomon, S., 1995. The microscopic representation of complex systems. In: Stauffer, D., (Eds). Annual Review of Computational Physics II. London: World Scientific.

[42] Stanley, M., Amaral, L., Buldyrev, S., Havling, S., Leshorn, H., Maas, P., Salinger, M., Stanley, E., 1996. Scaling behavior in the growth of companies. Nature 379, 804-806.

[43] Subbotin, M.T., 1923. The law of frequency of error. Mathematicheskii Sbornik 31, 296-301.

[44] Tesfatsion, L., 2007. Website on Validation of ACE: http://www.econ.iastate.edu/tesfatsi/empvalid.htm.

[45] Troitzsch, K., 2004. Validating simulation models. Proceedings of the 18th European Simulation Multiconference, SCS Europe, 98-106.

[46] Vagliasindi, P., Cirillo, P., Verga, G., 2006. Imprese e mercato del credito in un modello agent-based. Rivista Internazionale di Scienze Sociali 114, 459-486.

[47] Zipf, G.K., 1932. Selective Studies and the Principle of Relative Frequency in Language. Cambridge: Cambridge Press. 


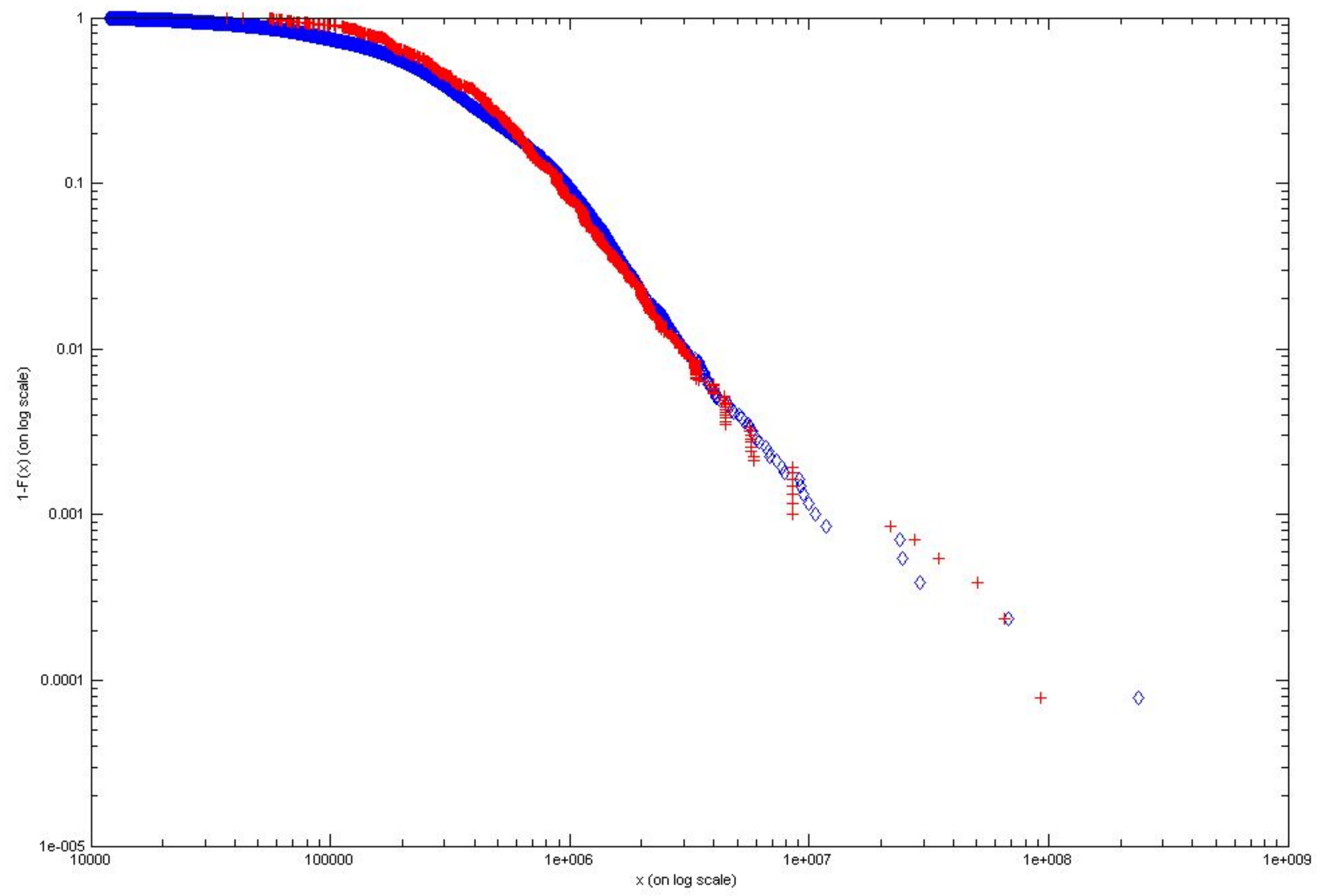

Page 21 of 34 
ACCEPTED MANUSCRIPT

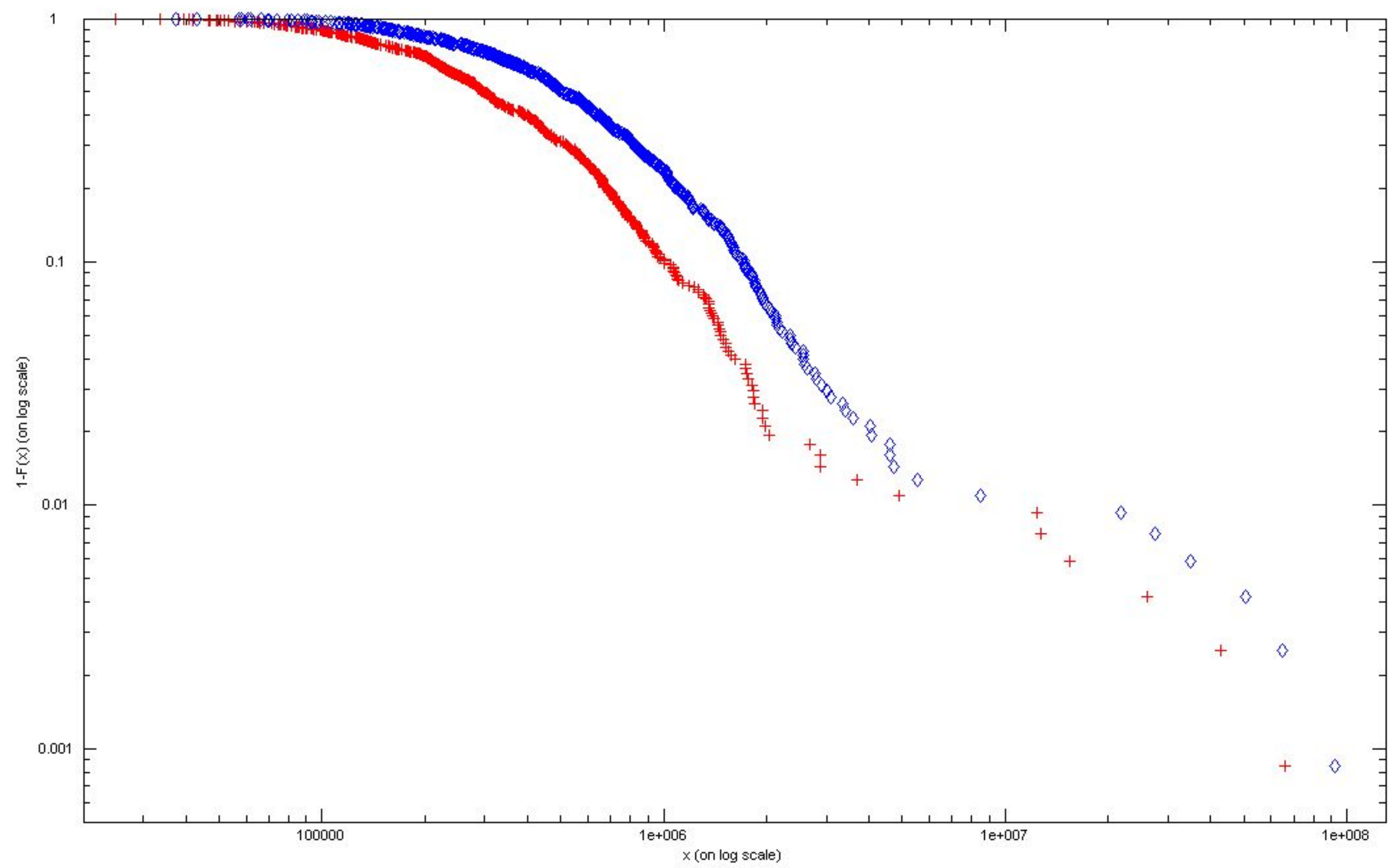

Page 22 of 34 


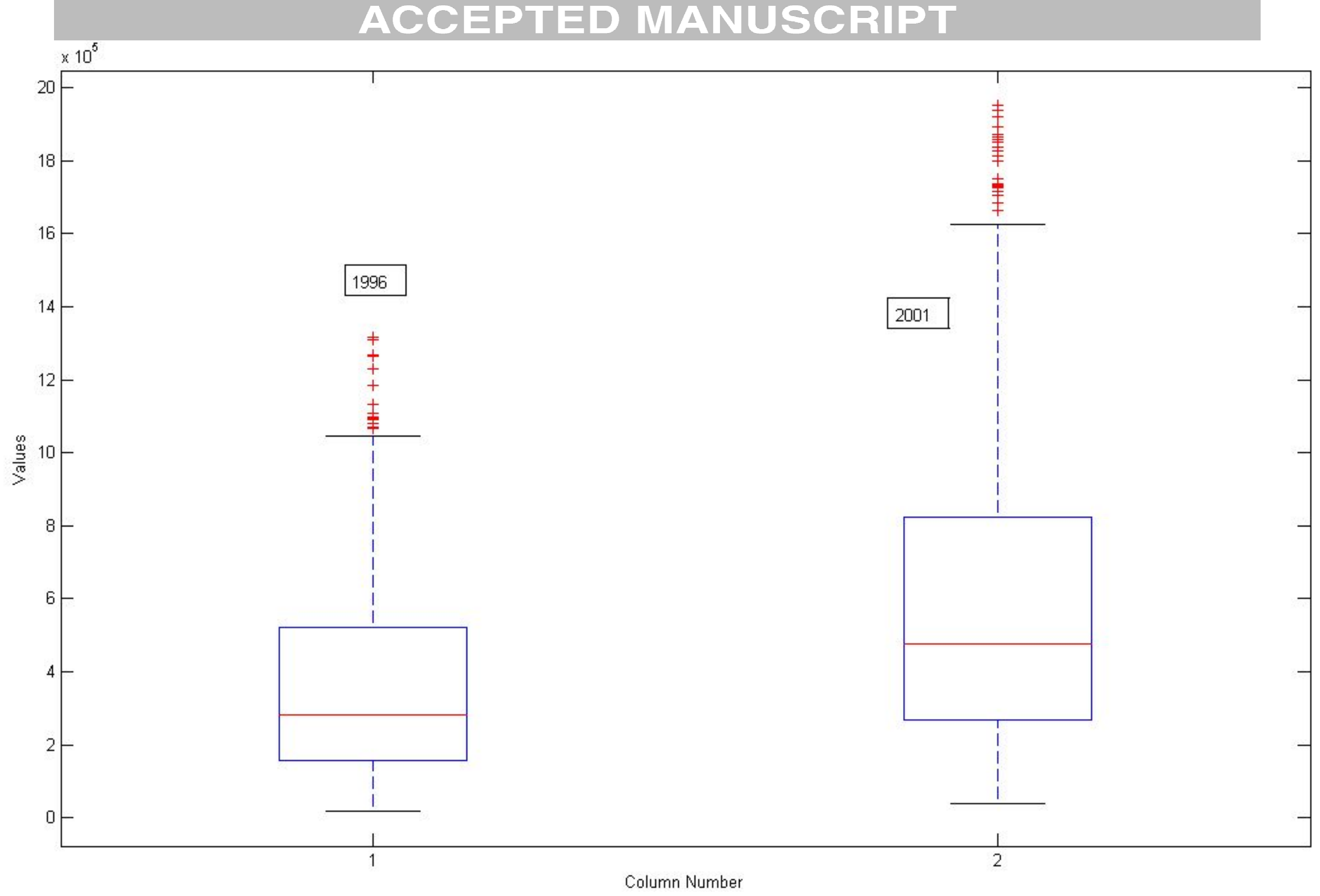

Page 23 of 34 
ACCEPTED MANUSCRIPT

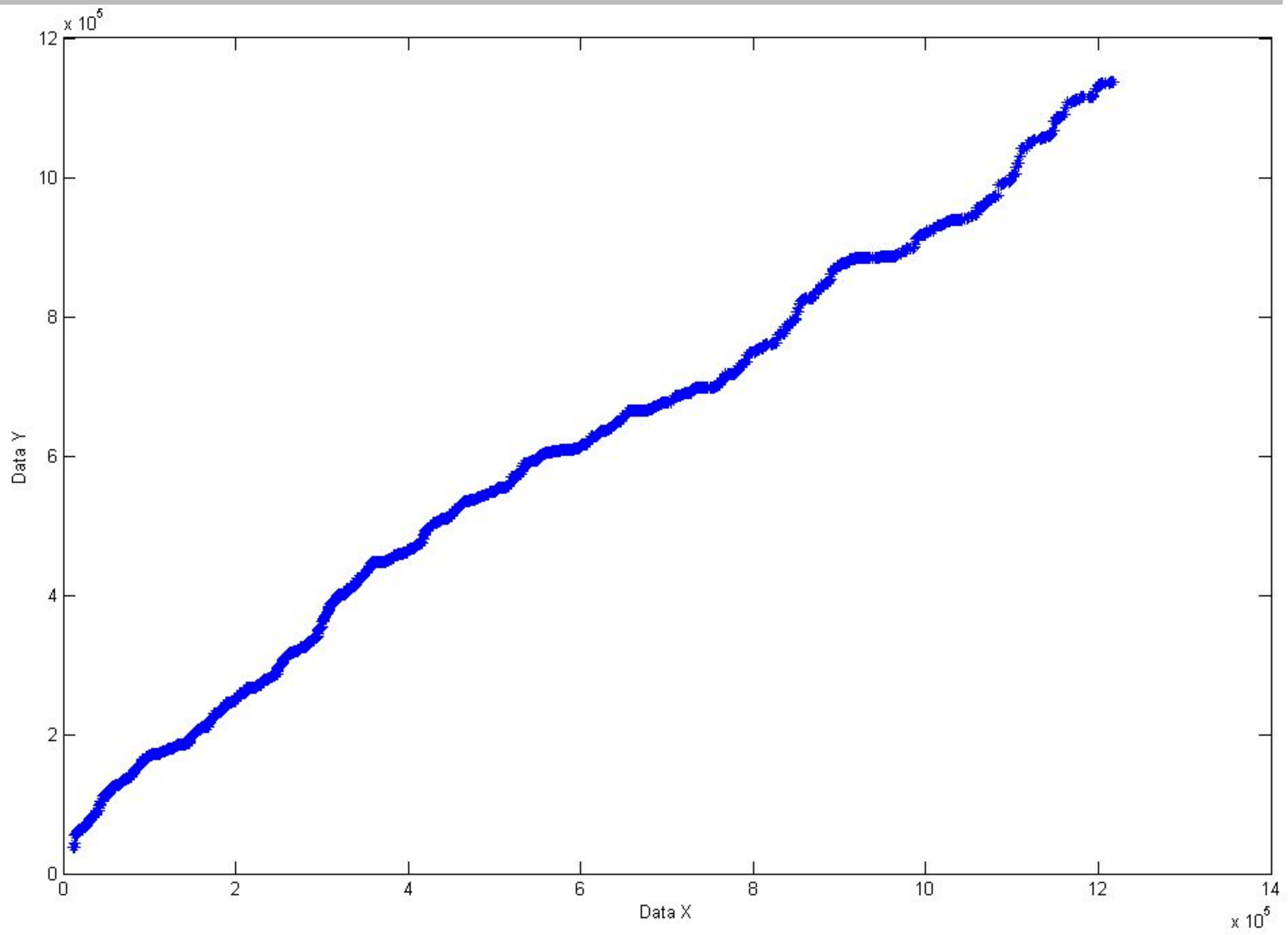

Page 24 of 34 


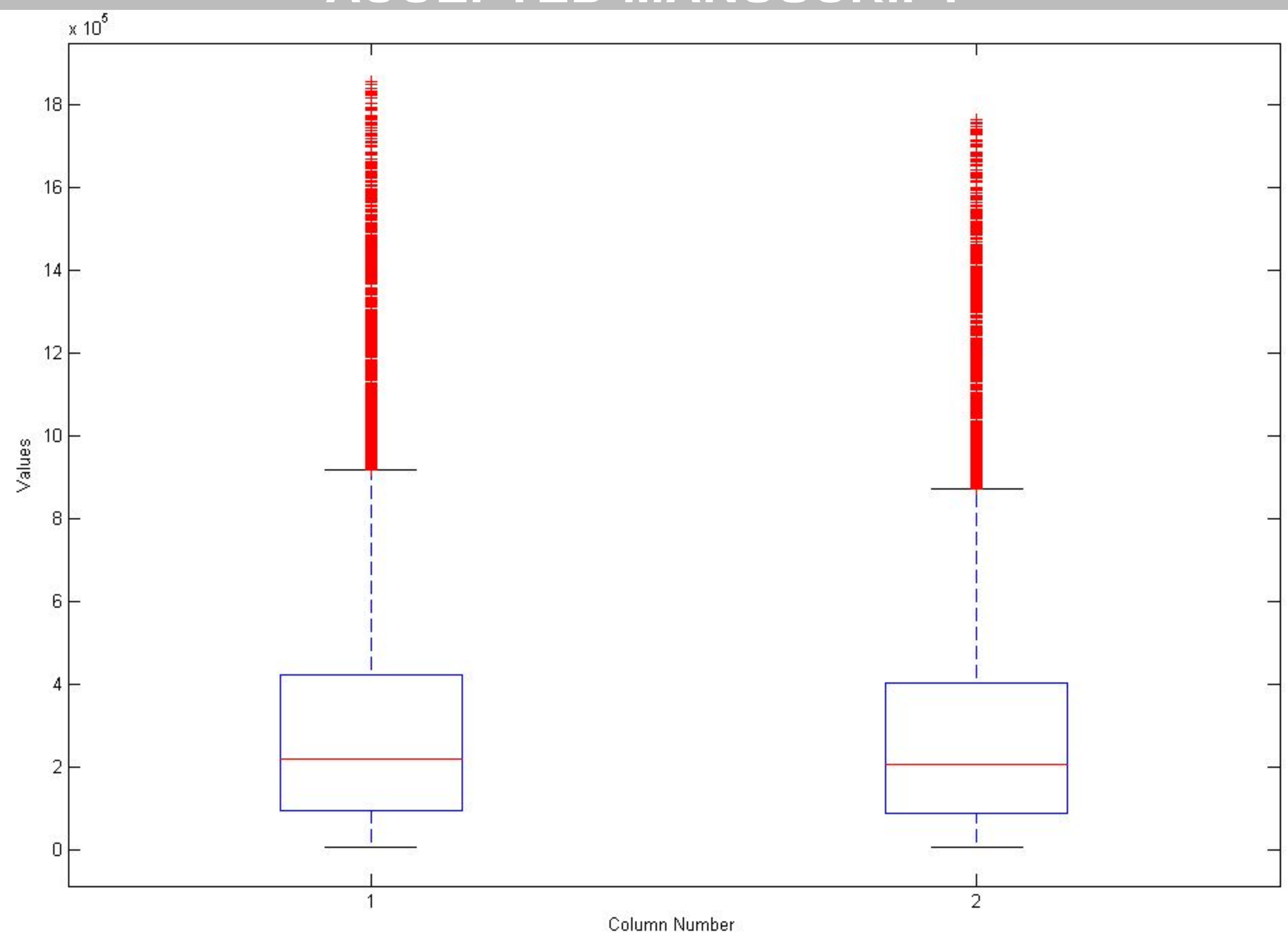

Page 25 of 34 
ACCEPTED MANUSCRIPT

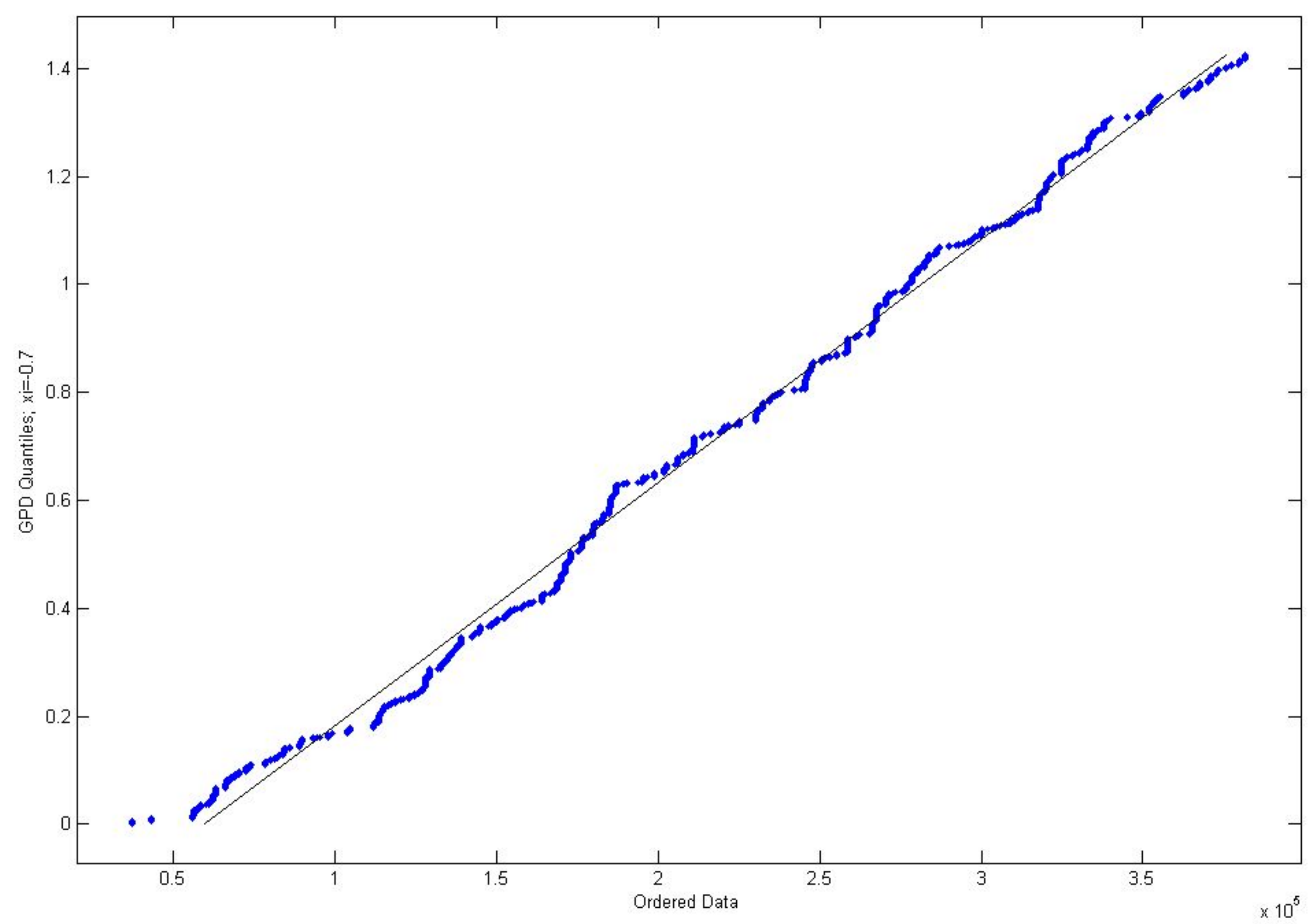

Page 26 of 34 


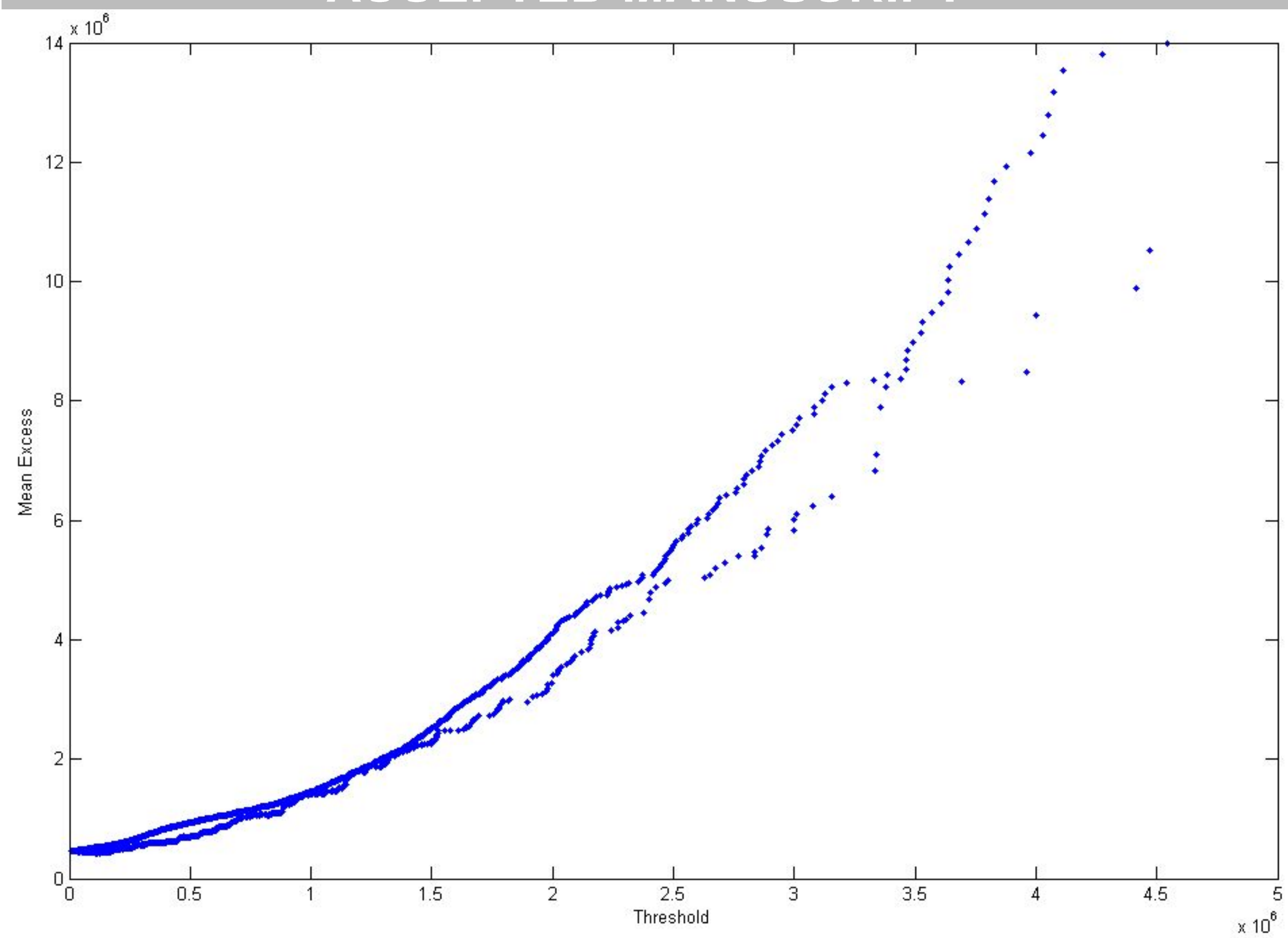

Page 27 of 34 


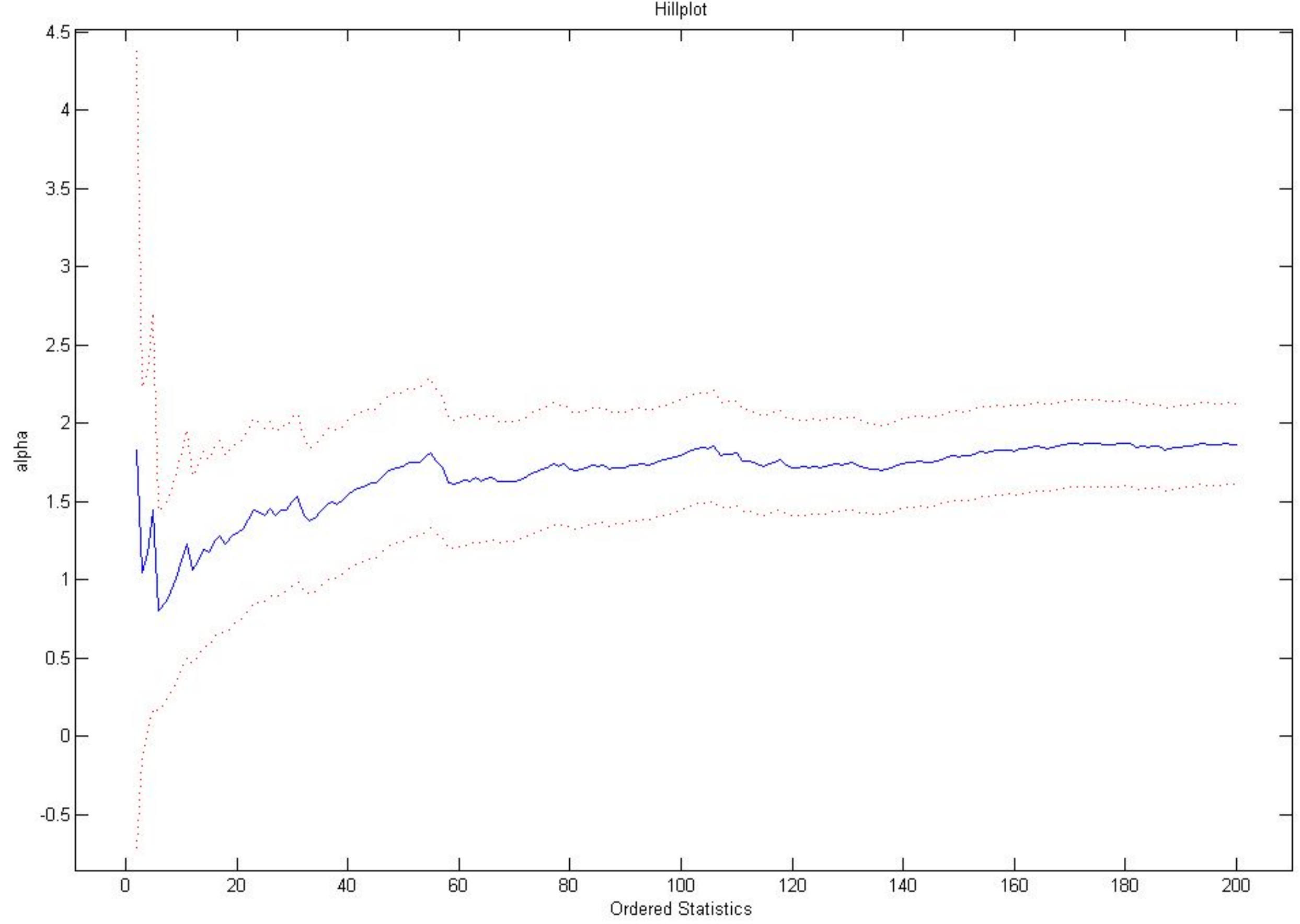

Page 28 of 34 
ACCEPTED MANUSCRIPT

Hillplot

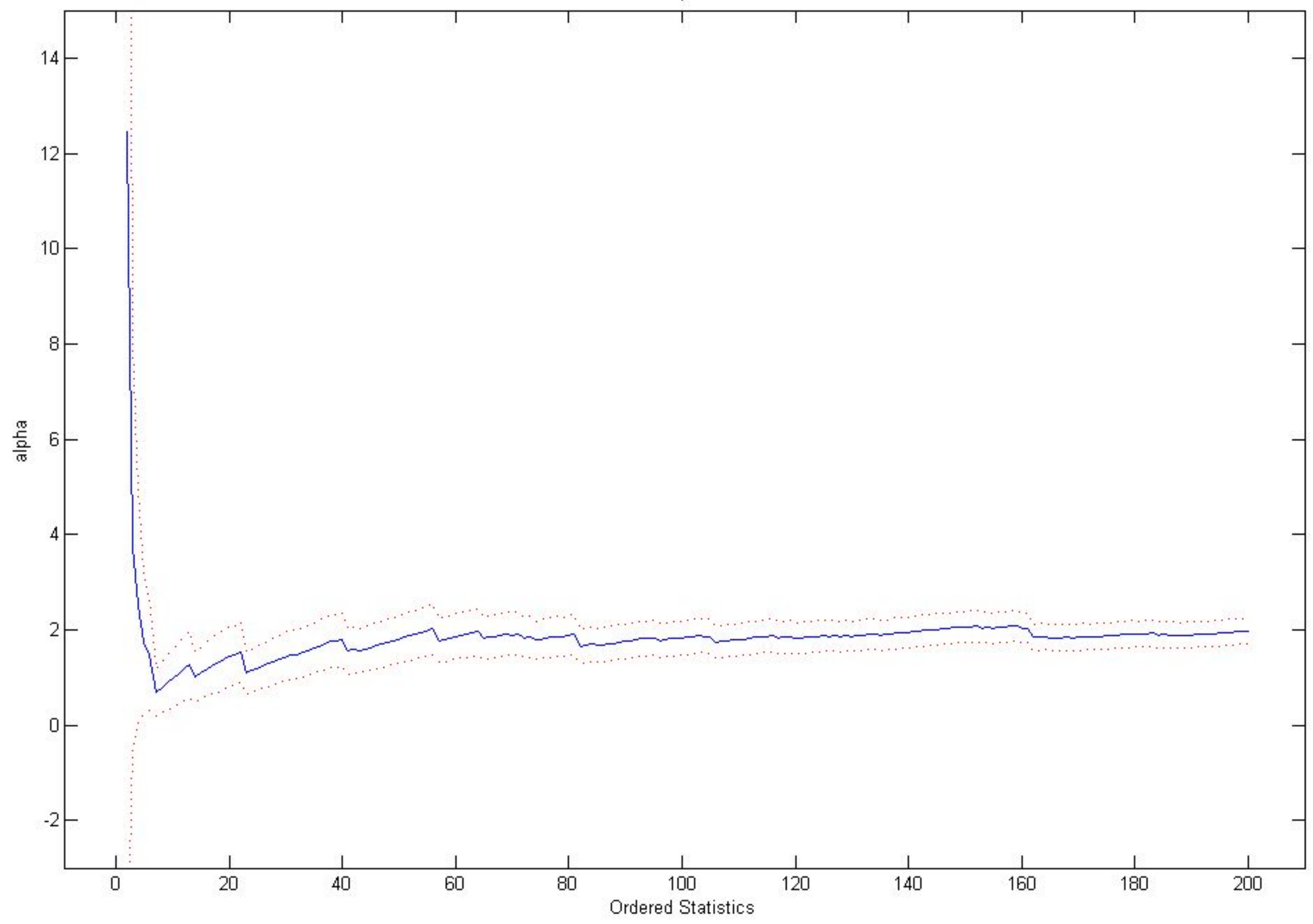

Page 29 of 34 


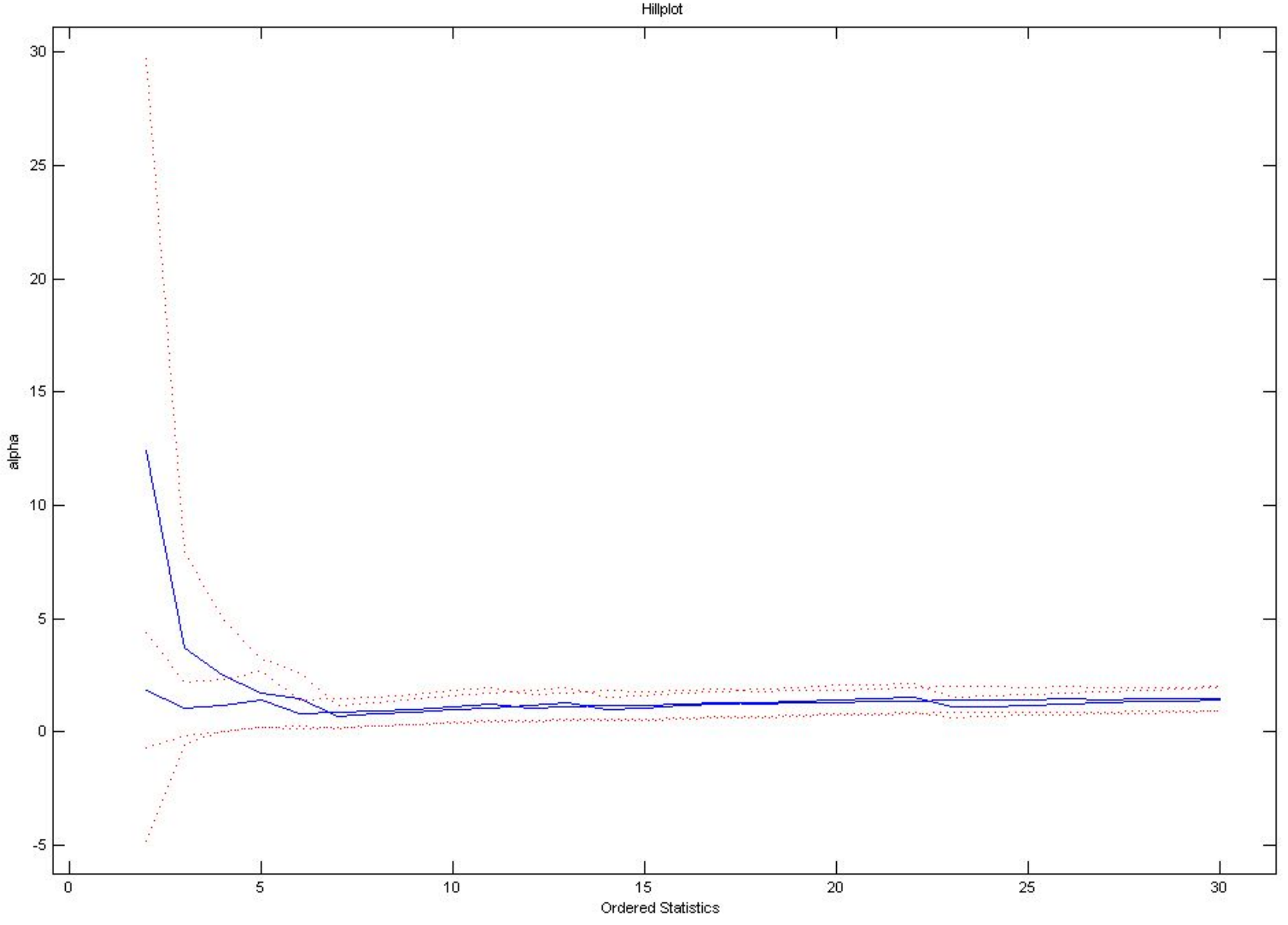

Page 30 of 34 


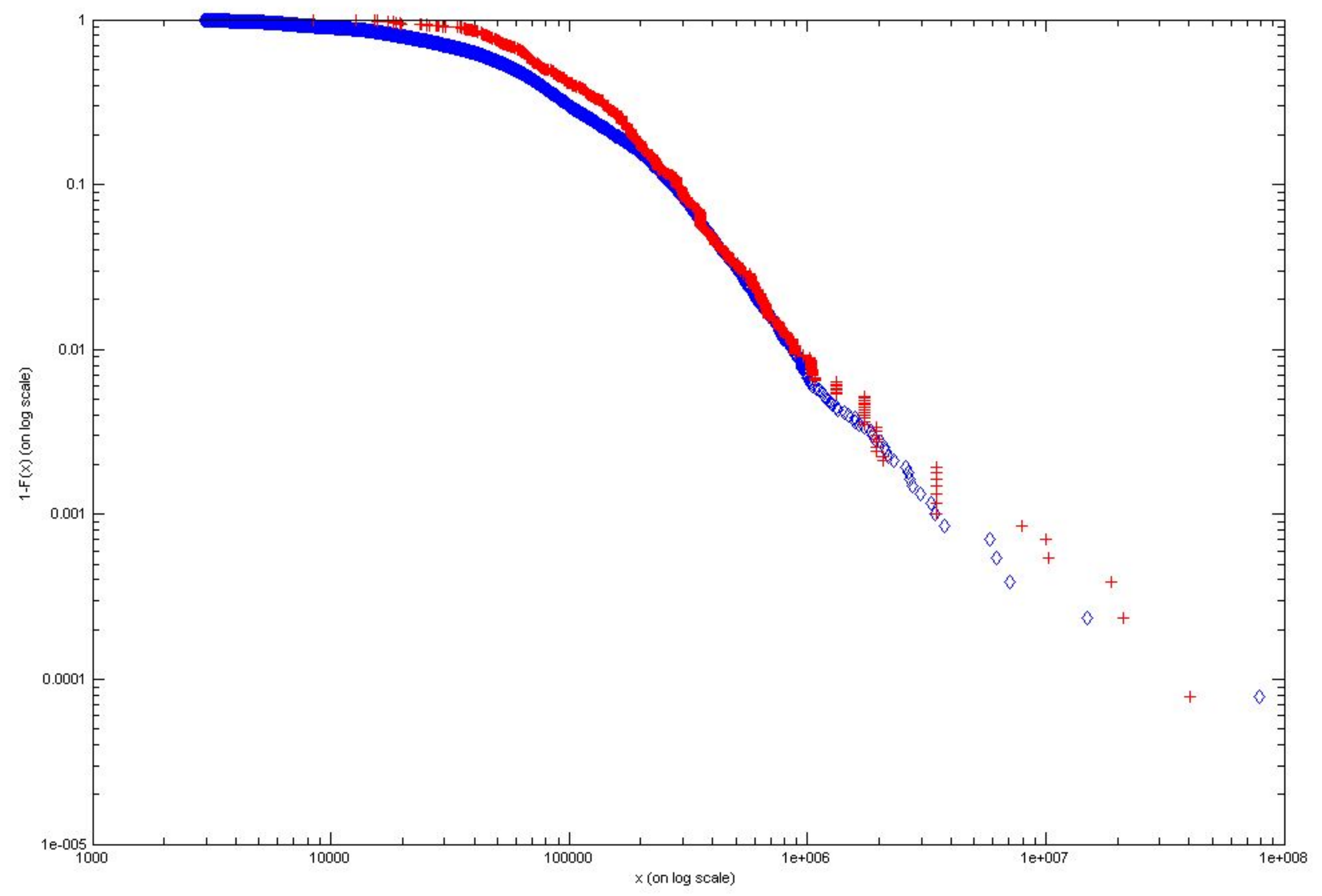

Page 31 of 34 
ACCEPTED MANUSCRIPT

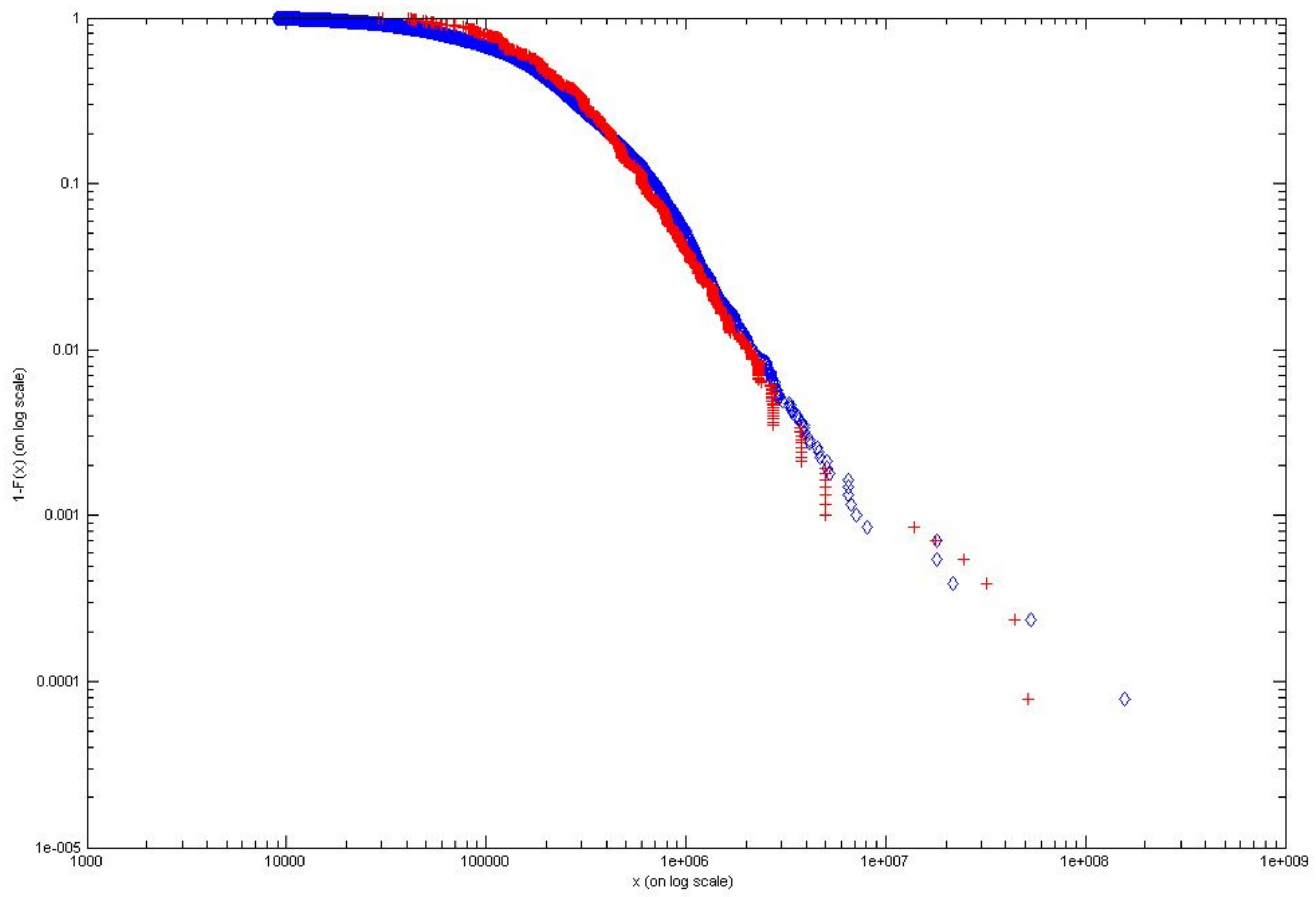

Page 32 of 34 


$$
\Lambda
$$


ACCEPTED MANUSCRIPT

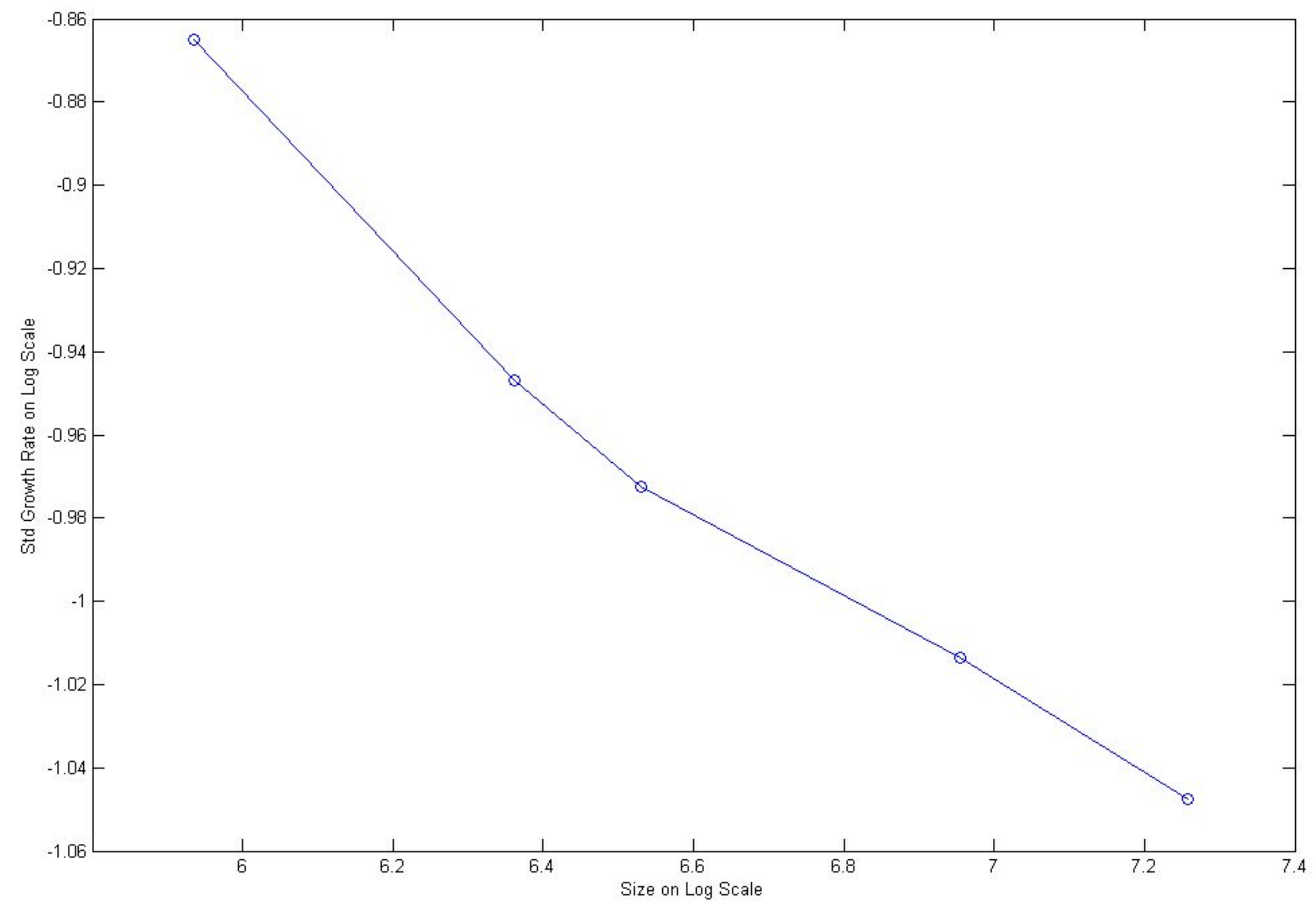

Page 34 of 34 